\title{
Mandibular Tooth-supported Overdenture using Customized Ball Attachments: A Clinical Research
}

\author{
${ }^{1}$ Anshul Chugh, ${ }^{2}$ Sanju Malik, ${ }^{3}$ Sunita Rani
}

\begin{abstract}
Tooth-supported overdentures are selectively supported from retained teeth and residual ridge. It helps to maintain the proprioception and preservation of remaining alveolar bone. Use of precision attachments provides with increased retention and gives an excellent sense of satisfaction to the patient. This clinical report describes the use of custom-made ball attachments to retain the tooth-supported mandibular overdenture.
\end{abstract}

Keywords: Custom-made attachments, Metal copings, Overdenture, Precision attachments, Retained teeth.

How to cite this article: Chugh A, Malik S, Rani S. Mandibular Tooth-supported Overdenture using Customized Ball Attachments: A Clinical Research. Int J Oral Implantol Clin Res 2017;8(2\&3):81-84.

Source of support: Nil

Conflict of interest: None

\section{INTRODUCTION}

Elderly population in today's world has better knowledge about their oral health care and more demanding toward their treatment from clinicians than previous generation. Therefore, clinicians should be aware of all types of prosthodontic treatment option available for the elderly population. Fabrication of a mandibular complete denture has always been a challenge to the prosthodontist, which offers adequate retention, support, stability, and most importantly provides comfort and satisfaction to the patient. ${ }^{1}$

Their retention tend to remain more prosthesis that comes and rests on one or more remaining natural teeth, the roots of the natural teeth, and/or a dental implant. Overdenture, be it implant-supported or tooth-supported, provides with a sensory input from periodontal receptors, alveolar bone preservation, occlusal forces that are substantially increased, which in turn increases the masticatory

\footnotetext{
${ }^{1}$ Associate Professor, ${ }^{2,3}$ Postgraduate Student

${ }^{1-3}$ Department of Prosthodontics, Pt. Bhagwat Dayal Sharma, Postgraduate Institute of Dental Sciences, Rohtak, Haryana, India

Corresponding Author: Anshul Chugh, Associate Professor, Department of Prosthodontics, Pt. Bhagwat Dayal Sharma, Post graduate Institute of Dental Sciences, Rohtak, Haryana, India e-mail: dr.anshulchugh@rediffmail.com
}

efficiency. ${ }^{1,2}$ Using natural teeth as abutment for denture considerably reduces the progress of residual ridge resorption. It is one of the favored treatment modalities for the elderly patient who has few remaining teeth. It is always justifiable to retain the natural root for overdentures than placing implants by extracting them.

Over the past decades, it has become important to save a natural tooth and using it as an abutment for construction of overdenture. There are various attachment systems available for tooth-supported overdenture., ${ }^{3,4}$ Their retention tends to remain more or less the same, hence increasing the compliance of the patient. Attachment systems help to connect either individual teeth or splinted teeth to prosthesis. ${ }^{5-7}$

\section{CASE REPORT}

A 59-year-old female reported to the Outpatient Department of Prosthodontics, Post Graduate Institute of Dental Sciences, Rohtak, Haryana, India, with a chief complaint of inability to chew food appropriately due to posterior missing mandibular teeth. No relevant medical history was given by the patient that can affect the dental treatment. Extraoral examination showed loss of vertical dimension, unsupported lip, and cheek musculature. There was no distortion of speech articulation. On intraoral examination, a completely dentulous maxillary arch was present with prosthetically rehabilitated 24, 25, 26, 27, and 16 and partially dentulous mandibular arch where $33,34,43$, and 44 were only teeth present (Fig. 1).

The various treatment options available for the patient's mandibular arch were either rehabilitation with implantsupported overdenture or extraction of the remaining teeth followed by conventional single denture or implantsupported overdenture. Patient rejected the option of an implant-supported overdenture due to longer duration of treatment phase, additional expenditure, and additional surgery. It was then decided to fabricate tooth-supported overdenture with custom-made extracoronal attachments.

Radiographic examination was done to evaluate the abutment periodontal health and crown-root ratio. Diagnostic maxillary and mandibular casts were made. Tentative jaw relation was recorded to determine the approximate vertical dimension of occlusion. Interarch space was found to be adequate. 

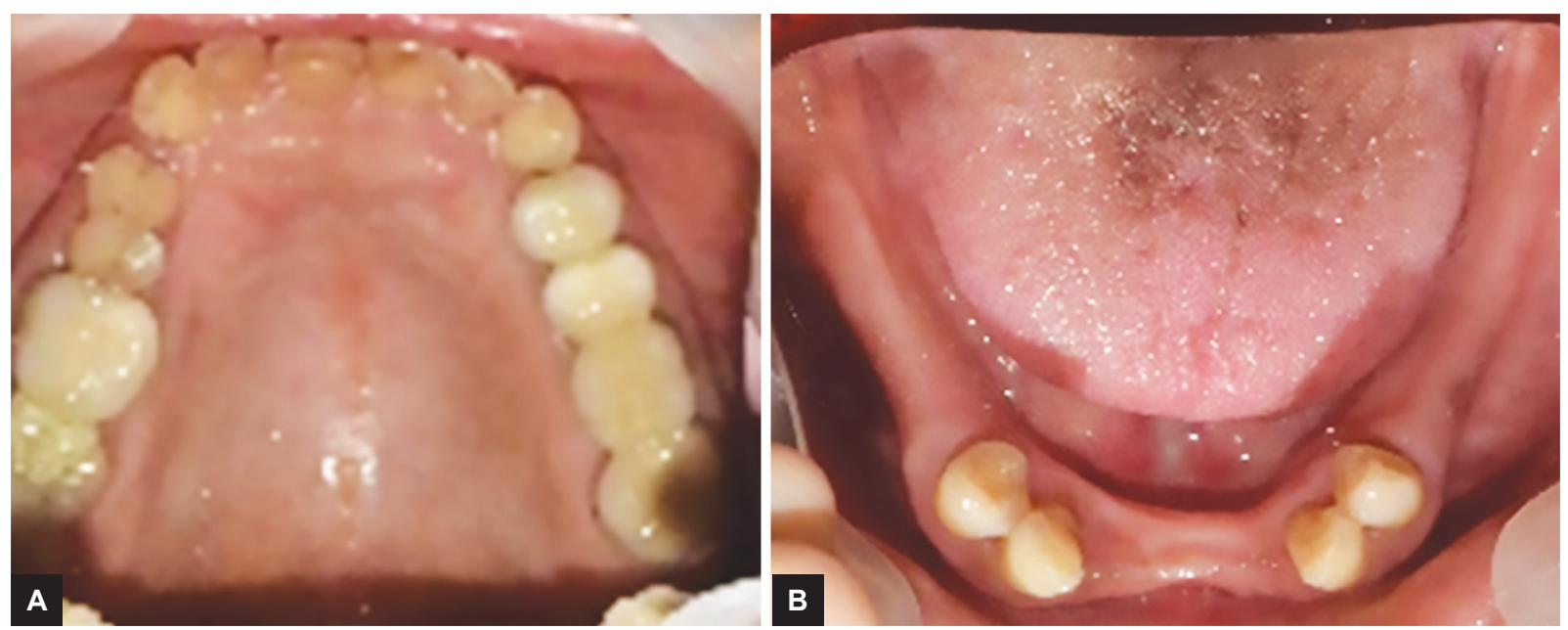

Figs $1 \mathrm{~A}$ and $\mathrm{B}$ : Intraoral maxillary and mandibular arch

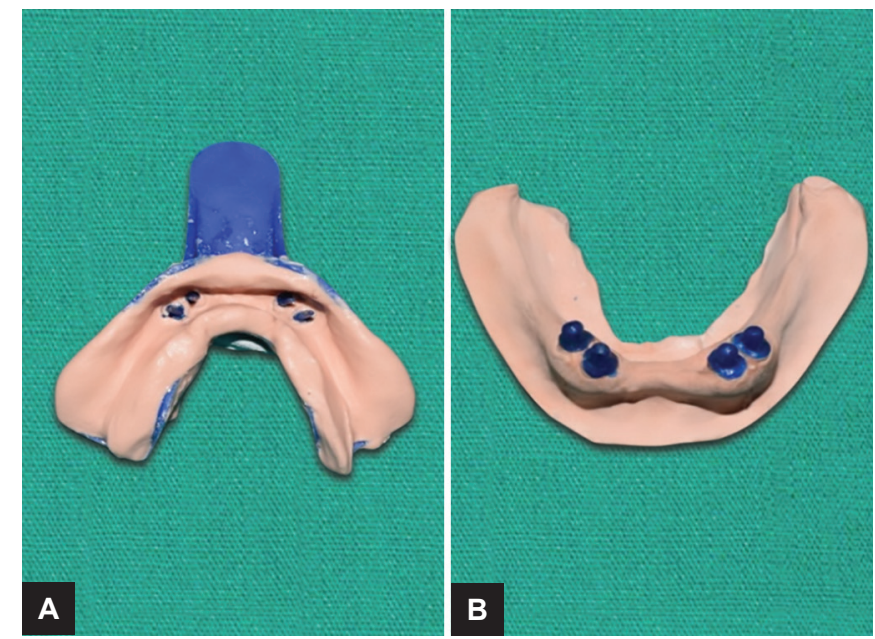

Figs 2A and B: (A) Final impression; (B) Wax pattern for custom attachments on mandibular cast

After the evaluation of diagnostic casts, it was decided to fabricate the mandibular overdenture using custom ball attachment (male component) with use of orthodontic separators as the retentive part (female component).

After thorough explanation of the treatment plan to the patient and taking her consent, treatment was started.

Elective endodontic treatment was carried out for 33, 34,43 , and 44, and then the coronal portion of teeth was prepared in dome-shaped contour and hemispherically round and reduced by leaving 3 to $4 \mathrm{~mm}$ projecting just above the gingival. Post space was prepared and custom post patterns were fabricated directly in root canal with blue inlay wax and a pick-up impression was made using alginate. The impression was poured with type IV die stone (Fig. 2).

The custom ball attachment was later fabricated and attached to the copings in the laboratory. Surveying was done over the cast to check the parallelism of the custom-made attachments. The casting was done using $\mathrm{CoCr}$ alloy in the laboratory using the conventional
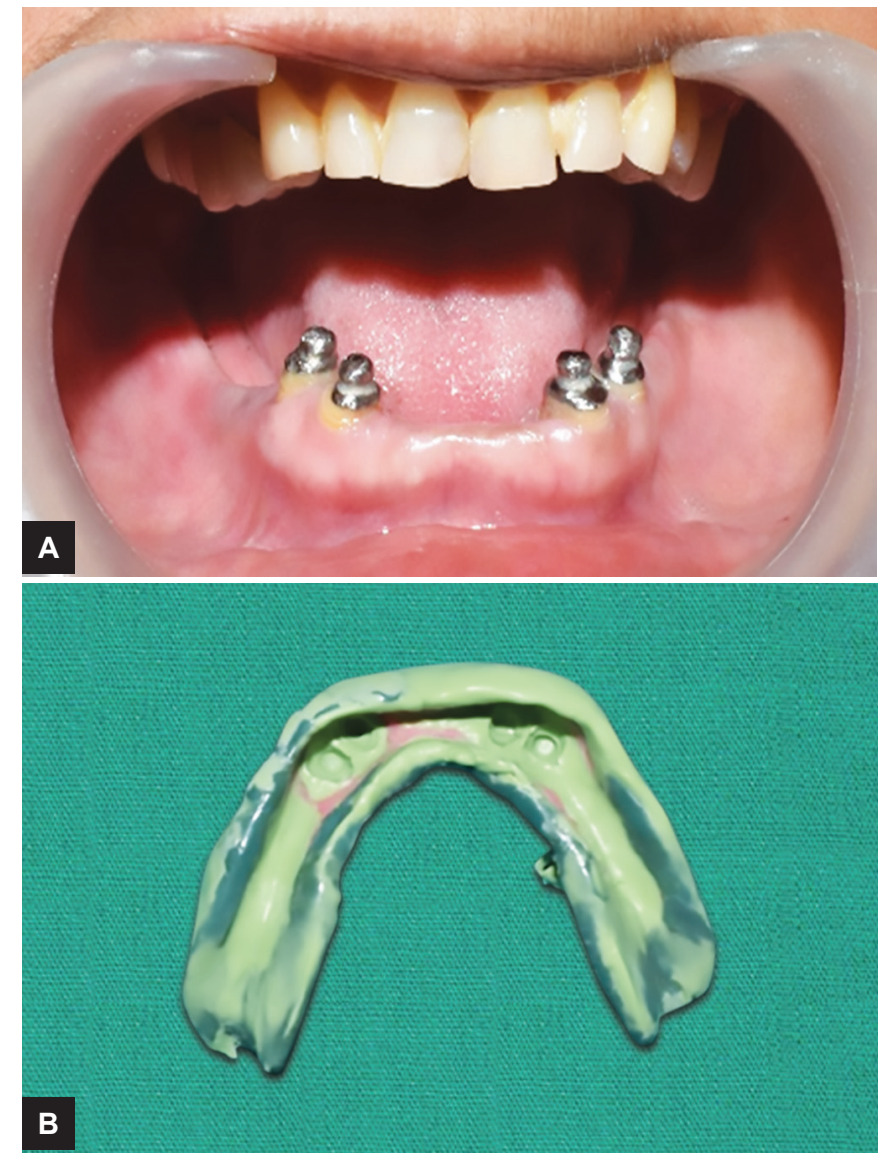

Figs 3A and B: (A) Cementation of custom-made attachments; (B) Mandibular arch final impression

techniques. The copings were finished and polished and then cemented in patient's mouth using glass ionomer cement.

Primary impression of the mandibular arch was made with irreversible hydrocolloid and primary cast was poured through it, which was used to fabricate special tray. Border molding was done using conventional procedures and final impression was made using medium viscosity rubber base material (Fig. 3). Occlusal bites were 
made and jaw relation was recorded. Teeth arrangement was done and try-in was evaluated in patient's mouth (Fig. 4). The waxed-up denture was cured using heat-cure acrylic resin.

Orthodontic separators were placed over the custom ball attachments and the intaglio surface of the denture was adjusted according to it. The separators were later picked up by adding auto-polymerizing resin in the space while maintaining the proper occlusion of mandibular denture and maxillary teeth (Fig. 5).

Excess of self-cure resin was trimmed off and denture was finished and polished again (Figs 6 and 7). The denture insertion was done and appropriate postinsertion instructions were given to the patient regarding insertion,
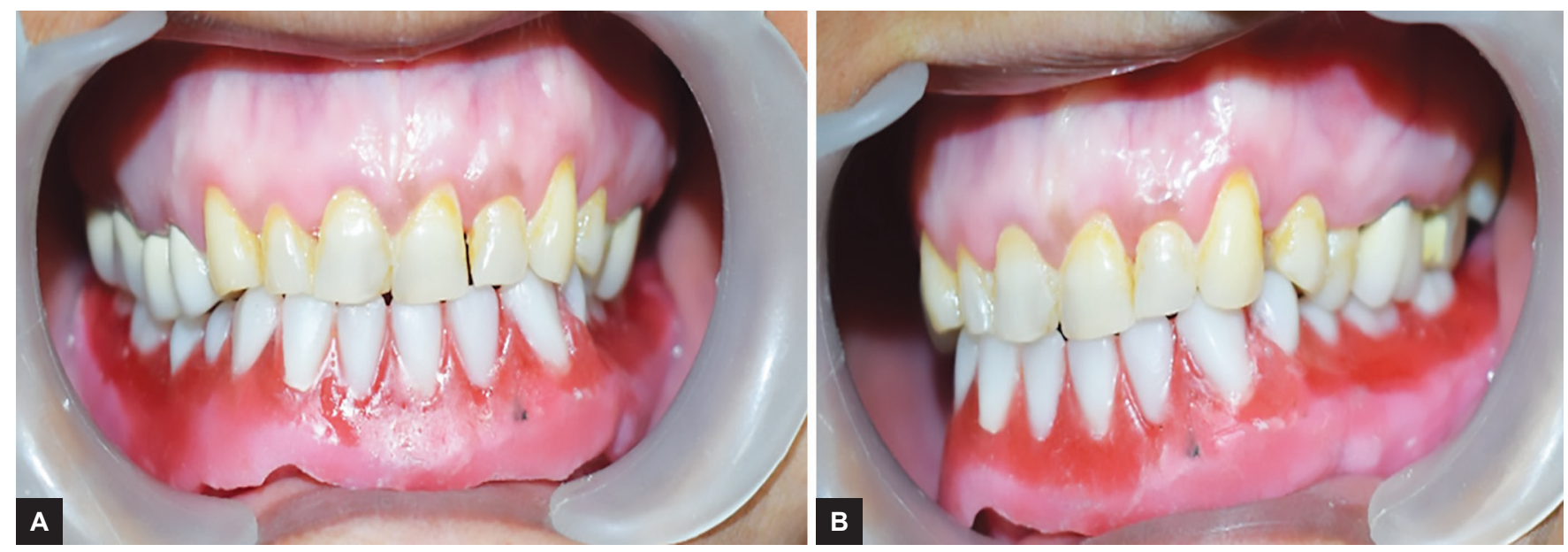

Figs 4A and B: Occlusal try-in
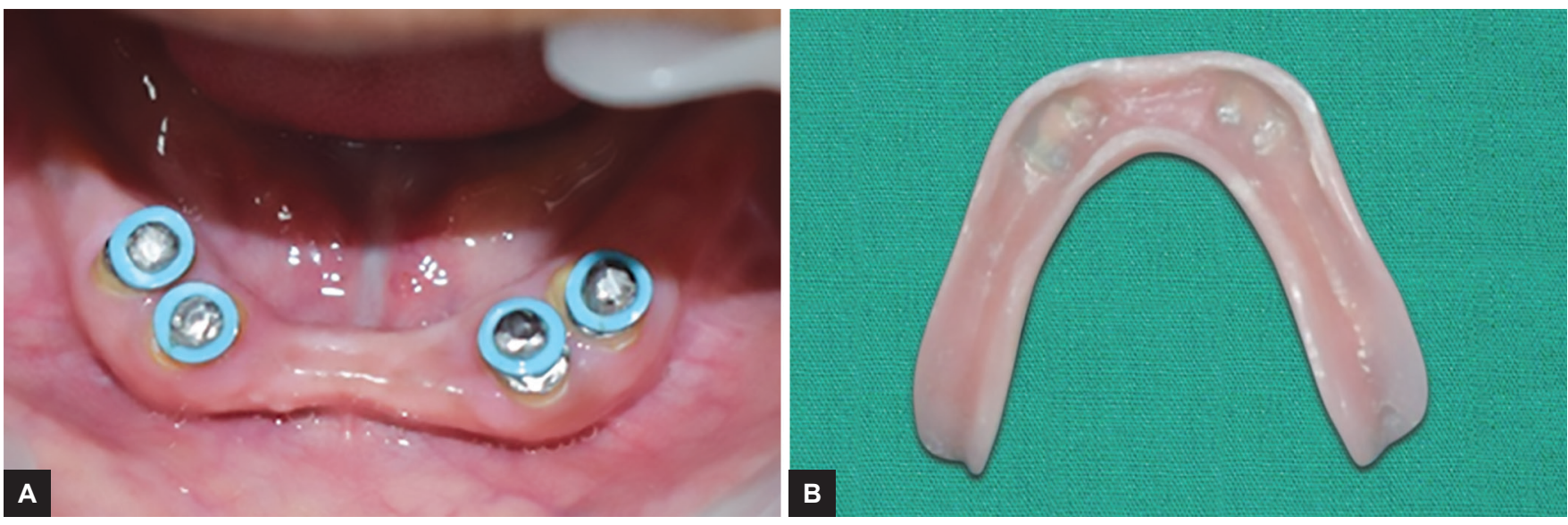

Figs 5A and B: (A) Orthodontic separators attached on custom attachments; (B) Processed mandibular denture

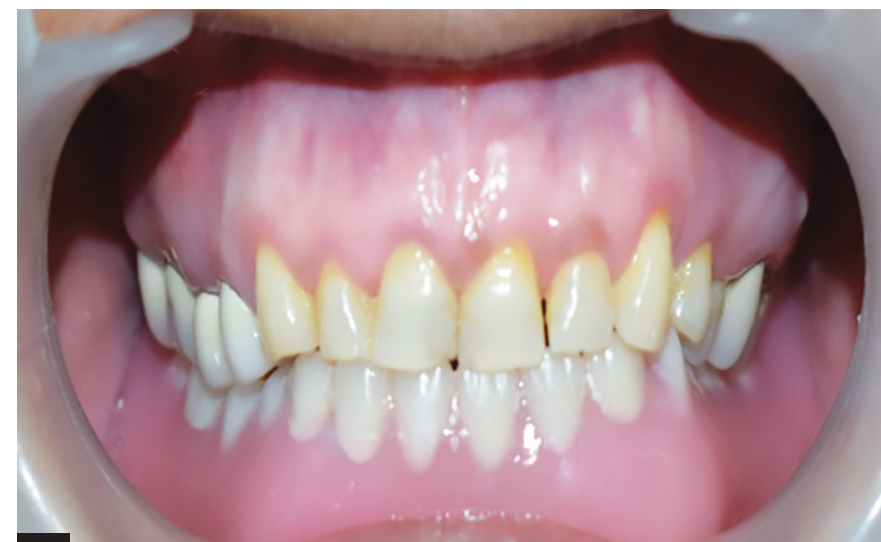

A

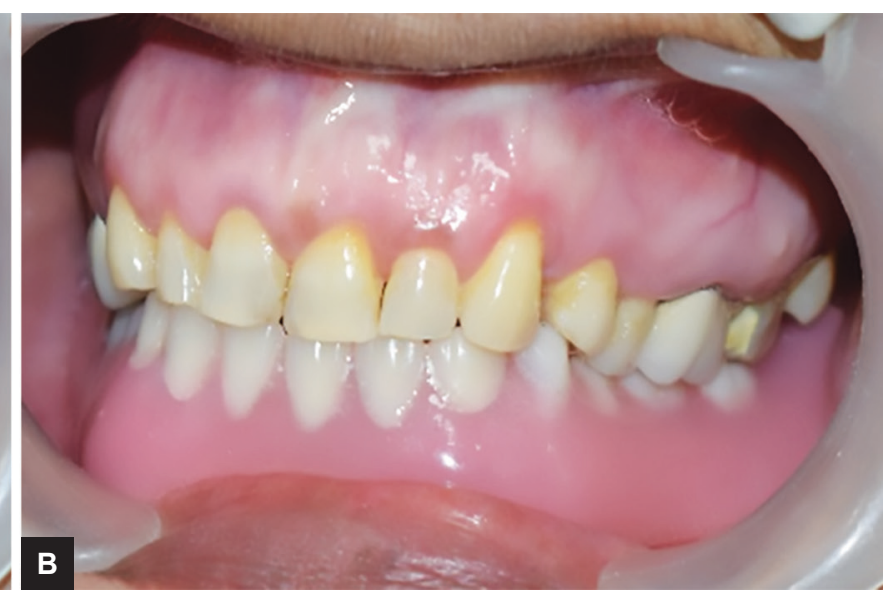

B

Figs $6 \mathrm{~A}$ and $\mathrm{B}$ : Denture insertion 


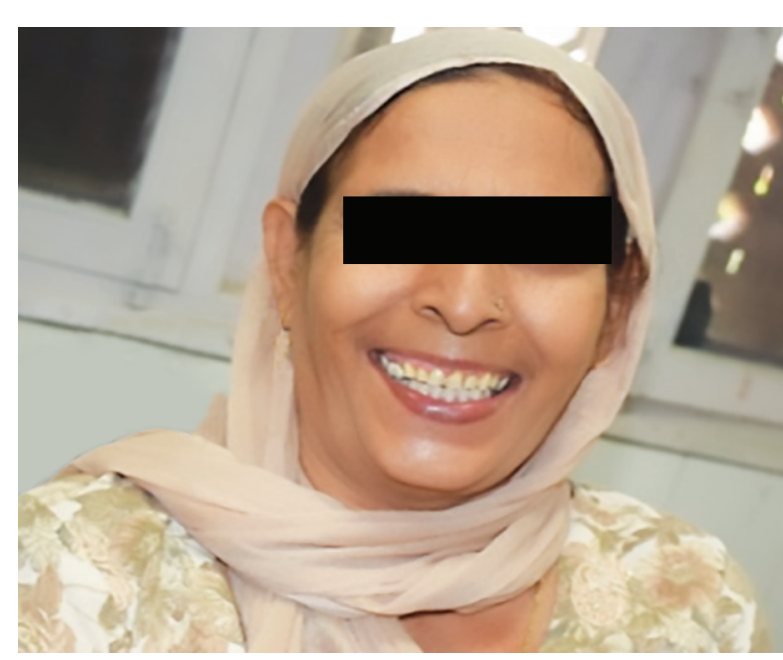

Fig. 7: Extraoral view postdenture insertion

removal, chewing, speech articulation, cleaning, as well as maintenance of the denture.

Periodic follow-up was done for the patient.

\section{DISCUSSION}

The preservation of supporting teeth as an overdenture abutment provides efficient prosthetic treatment. Toothsupported overdenture can be retained with precision attachments improving both retention and stability. ${ }^{9}$ Different overdenture designs are available including bar and clip, ball and O-ring, ERA, and magnetic attachment. 2,3,5-10 The keystone of success for an overdenture treatment is the selection of strategic abutments with endodontic and periodontal therapy to receive the attachment. ${ }^{4}$ The use of ball attachment provides a superior retention as well as it acts as a shock absorber and stress redirector. It is effortless to insert and remove and it is convenient for most of the patients. The metal OT cap attachment system is considered to be a good resilient attachment for overdentures. ${ }^{5,10-12}$

This technique using custom-made ball attachments and orthodontic separators provides with a simple and cost-effective alternative to the use of prefabricated attachment systems. Separators are relatively easy to use since the diameter of required dimension is available. Inner and outer diameters of the separator are 2.23 and $4.23 \mathrm{~mm}$ respectively. ${ }^{6,7}$ Ball attachments were at least made $1 \mathrm{~mm}$ larger to the inner diameter to provide the frictional retention.

\section{SUMMARY AND CONCLUSION}

Patients often complain of lack of retention while using complete mandibular removable denture. Implantsupported overdenture helps to overcome the issue but every patient cannot afford the treatment cost. In that situation, a tooth-supported overdenture may be advised to the patient if healthy teeth are remaining in the arch. Incorporation of precision attachments along with toothsupported overdenture brings out new treatment option and increases patient satisfaction.

\section{REFERENCES}

1. Dable RA, Gaikwad BS, Marathe SS, Badgujar MS, Dole VR. A simplified technique for custom made overdenture semi-precision attachments. Indian J Dent Res 2013 SepOct;24(5):622-626.

2. Tokuhisa M, Matsushita Y, Koyano K. In vitro study of a mandibular implant overdenture retained with ball, magnet or bar attachments: comparison of load transfer and denture stability. Int J Prosthodont 2003 Mar-Apr;16(2):128-134.

3. Ben-Ur Z, Gorfil C, Shifman A. Anterior implant-supported overdenture. Quintessence Int 1996 Oct;27(9):603-606.

4. Guttal SS, Tavargeri AK, Nadiger KK, Thakur SL. Use of an implant O-ring attachment for the tooth supported mandibular overdenture: a clinical report. Eur J Dent 2011 Jul;5(3): 331-336.

5. Schuch C, de Moraes AP, Sarkis-Onofre R, Pereira-Cenci T, Boscato N. An alternative method for the fabrication of a root supported overdenture: a clinical report. J Prosthet Dent 2013 Jan;109(1):1-4.

6. Bansal S, Aras MA, Chitre V. Tooth supported overdenture retained with custom attachments: a case report. J Indian Prosthdont Soc 2014 Dec;14(Suppl 1):283-286.

7. Samra RK, Bhide SV, Goyal C, Kaur T. Tooth supported overdenture: a concept overshadowed but not yet forgotten. J Oral Res Rev 2015 Jul;7(1):16-21.

8. DeFranco, RL. Overdentures. In: Winkler S, editor. Essentials of complete denture prosthodontics. 2nd ed. Littleton (MA): PSG Publishing Co; 1988. pp. 384-402.

9. Langer $Y$, Langer A. Root-retained overdentures: part I: biomechanical and clinical aspects. J Prosthet Dent 1991 Dec;66(6):784-789.

10. Berksun S. A laboratory made attachment application that can be used in overdentures. Ankara Univ Hekim Fak Derg 1989 Sep;16(3):505-509.

11. Nemcovsky CE, Fitzig S, Gross M. Custom overdenture retainer. J Oral Rehabil 1990 Jul;17(4):343-350.

12. Burns DR. The mandibular complete overdenture. Dent Clin North Am 2004 Jul;48(3):603-623. 